\title{
Discontinuous shock and generalization to the preshock period in discriminated avoidance learning ${ }^{1}$
}

JOHN H. HESS AND JAMES N. SHAFER WEST VIRGINIA UNIVERSITY

Discontinuous shock has been shown to have a facilitating effect upon discriminated bar-press avoidance learning. The effect has been attributed to enhanced generalization of escape responses to the preshock period. Since the factor crucial to enhanced generalization is presumed to be the occurrence of escape responses in the absence of shock, it was hypothesized that presentation of shock in what otherwise would have been off-shock periods, should inhibit avoidance learning. The avoidance performance of animals trained under standard discontinuous shock was compared with that of animals receiving an additional burst of shock contingent upon each escape response. Nonsignificant differences appeared between treatment groups and were in the opposite direction to that expected. It was concluded that rather than producing an increase in generalization, discontinuous shock improves the quality of the response generalized.

The facilitative effect of a discontinuous shock (UCS) in conditioning a lever-press avoidance response has been established (D'Amato, Keller, \& DiCara, 1964; Hurwitz, 1964), and parameters of shock on-off times (D'Amato, Keller, \& Biederman, 1965) and shock intensity (D'Amato \& Fazzaro, 1966) have been investigated. It has been hypothesized (D'Amato, Keller, \& DiCara, 1964) that failure to learn to avoid under conditions of continuous shock was due in part to inadequate generalization of the escape response to the preshock period. In support of the generalization hypothesis, D'Amato, Keller, \& Biederman (1965) report a high correlation between the percentage of escape responses executed during off time and avoidance performance. The present experiment provides a further test of the generalization hypothesis by comparing avoldance behavior of Ss tested under conditions wherein each escape response produces a $.2 \mathrm{sec}$ shock with that of Ss tested under standard discontinuous shock procedures. Since the factor crucial to enhanced generalization with discontinuous shock is presumed to be the occurrence of escape responses in the absence of shock, the presentation of shock in what otherwise would be an off-shock period should inhibit avoidance learning.

Mnthod

The Ss, 20 male Sprague-Dawley rats obtained from Research Animals, Inc., Pittsburgh, Pa., were randomly assigned to an experimental group which received response contingent shock on each escape trial or a control group trained under standard dis- continuous shock procedure. The experiment was carried out in two replications with an age and/or time of testing comparison included within each of the treatment groups. One half the animals in each treatment group had a mean age of 60 days and one half a mean age of 80 days when tested.

On Day 1 the bar-pressing response was shaped and each $S$ was given 30 trials of escape-avoidance training with $.3 \mathrm{~mA}$ continuous shock. The CS was a combination of a $4000 \mathrm{cps}$ tone at $60 \mathrm{~dB}$ and a $12 \mathrm{~V}$ pilot light mounted in the celling of a conventional Skinner box at the end opposite the bar. A variable 35 sec intertrial interval and a 5 sec CS-UCS interval was used for all trials.

On Day 2, Ss received 300 escape-avoidance trials under discontinuous shock $(.2 \mathrm{sec}$ on-time and $2.0 \mathrm{sec}$ off-time) of a $.2 \mathrm{~mA}$ intensity. In addition, $\mathrm{Ss}$ in the experimental group received a $.2 \mathrm{sec}$ burst of shock of the same intensity contingent with each escape response.

\section{Results and Discussion}

A Hartley's analysis of variance for homogeneity of avoidance scores revealed heterogeneity of variance. Escape data were substituted for avoldance data to correct for negative skewness and a square root transformation was performed. A Lindquist III analysis of variance showed significant differences between control and experimental groups on trials and age. The overall avoidance scores of 60 day old animals were superior to those of 80 day old animals $(F=4.57, d f=1 / 16, p<$ $.05)$. A similar analysis of the number of shocks received by Ss on escape trials revealed that 60 day old animals received significantly fewer shocks than the 80 day old animals $(F=6.55$, df $=1 / 16, p<.05)$. The avoidance performance is illustrated in Fig. 1.

Employing a shuttlebox escape-avoidance training task, Brush (1966) reported that maximum escape latency differentiated Ss making 2 and 3 avoidance responses from those making 0 and 1 avoldance responses, and is the best predictor of rate of learning among learners. In the present study, the 60 day old group obtained signiflcantly better avoidance scores than the 80 day old group while exhibiting significantly shorter escape latencies (as measured in the number of shocks received on escape trials). These results appear to suggest a relationship between escape latency and avoidance performance of different age groups as well as within a single sample of Ss at a given age.

The results fail to support the hypothesis (D'Amato, 


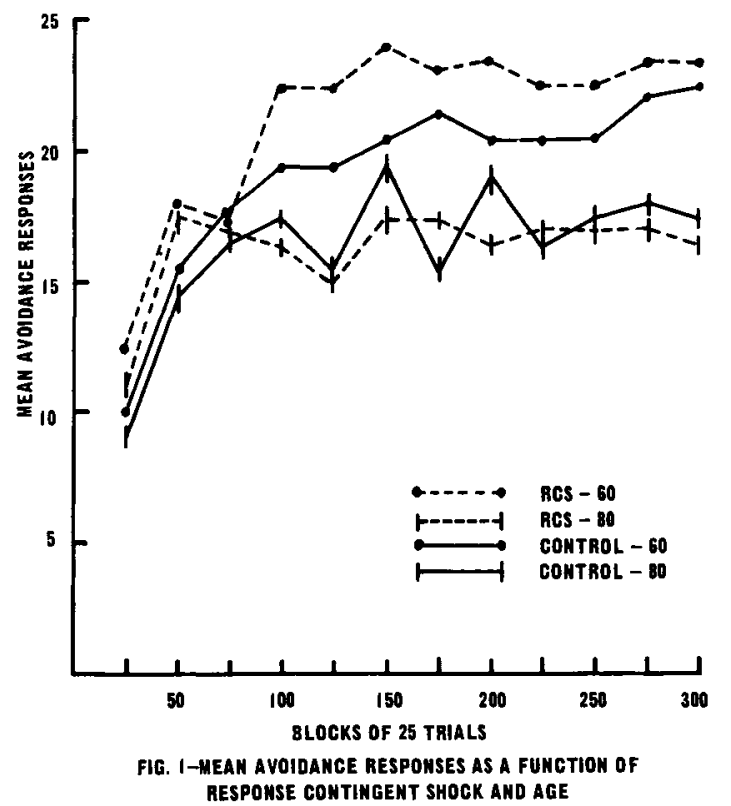

Keller \& DiCara, 1964) that discontinuous shock enhances generalization of the escape response to the preshock period. S's tested under conditions arranged so that each escape response occurred in the presence of shock, performed as well as Ss tested under standard discontinuous shock procedures.

It is interesting to note that D'Amato, Keller \& Biederman (1965) found that approximately $33 \%$ of the escape responses over the first 100 trials fell in a 2 sec shock-off period while $77 \%$ occurred during a .450 sec period which included the .2 sec shock-on time and the following $.25 \mathrm{sec}$. Two interpretations of these data are suggested. Either Ss are pacing their responses or they are responding to the discrete shock presentation. The Ss' behavior suggests the second alternative since it has been reported (D'Amato, Keller \& DiCara, 1964), and it has been our observation, that Ss tested under the condition of continuous shock would often approach the bar with the onset of the CS, position their paws above it and wait for the shock before responding. The behavior of approaching the bar with the onset of CS suggests a conflict between responding and not responding to the bar. Such conflict behavior would be predicted if it were assumed that, in addition to removing an aversive stimulus, the escape response results in an increase in the effective shock intensity perhaps by virtue of the requirement that to complete the response the $S$ must raise on his hind paws thus changing the current density. With discontinuous shock (long off periods and short on periods) a number of escape responses will occur in an off period thus decreasing the association between an increase in shock intensity and the to-be-learned response compared with the continuous shock procedure wherein all responses are made in the presence of shock. The results of the present experiment, however, fail to support either a generalization hypothesis or a shock density hypothesis. Conditioning with discontinuous shock wherein each escape response produces the aversive stimulus did not result in poorer avoidance performance.

\section{References}

BRUSH, F. R. On the differences between animals that learn and do not learn to avoid electric shock. Psychon. Sci., 1966, 5, 3, 123-124.

D'AMATO, M. R., \& FAZZARO, J. Discriminated lever-press avoidance learning as a function of type and intensity of shock. J. comp. physiol. Psychol., 1966, 61, 313-315.

D'AMATO, M. R., KELLER, D., \& BIEDERMAN, G. Discriminated avoidance learning as a function of parameters of discontinuous shock. J. exp. Psychol., 1965, 70, 543-548.

D'AMATO, M. R., KELLER, D. M., \& DICARA, L. Facilitation of discriminated avoidance learning by discontinuous shock. $J$. comp. physiol. Psychol, 1964, 58, 344349.

HURWTT, H. M. B. Method for discriminative avoidance training. Science, 1964, 145, 1070.

Note

1. This research was based upon a Master's thesis by the first author under the direction of the second and supported in part by United States Public Health Service Grant MH 1163401. 